\title{
Metal-Free Stereoselective Cationic Polymerization of Vinyl Ethers by Employing a Confined Bronsted Acid as the Catalyst
}

\author{
Zan Yang, ${ }^{+}$Xun Zhang, ${ }^{\dagger}$ Yu Jiang, ${ }^{\dagger}$ Qiang Ma, ${ }^{\dagger}$ and Saihu Liao, ${ }^{*,+,}$
}

'Key Laboratory of Molecule Synthesis and Function Discovery (Fujian Province University), State Key Laboratory of Photocatalysis on Energy and Environment, College of Chemistry, Fuzhou University, Fuzhou 350108, China

${ }^{\ddagger}$ Beijing National Laboratory for Molecular Sciences, Beijing 100190, China

Supporting Information Placeholder

\begin{abstract}
The properties of poly(vinyl ether)s (PVEs) are highly dependent on their tacticity, and the appealing thermoplastics features of isotactic PVEs have drawn considerable efforts to develop stereoselective cationic polymerization methods to access this class of polymers. However, reported methods that could achieve a high degree of tacticity control are limited to process employing metal-based Lewis acids, and with various limitations on catalyst loading, monomer scope, etc. Here, we introduce a metal-free stereoselective cationic polymerization of vinyl ethers by employing a class of chiral confined Brønsted acids, imidodiphosphorimidates (IDPis), as the catalyst. This organocatalytic approach features its metal free conditions, high efficiency, high stereoselectivity, single catalyst system, operation simplicity, etc.
\end{abstract}

The tacticity of polymers being a critical factor affects the properties (e.g. mechanical strength, thermal performance, optical property etc.) of materials. ${ }^{1}$ For example, atactic polypropylene is typically an amorphous fluid; in contrast, isotactic polypropylene is a crystalline, rigid thermoplastic, while syndiotactic polypropylene processes greater impact strength and better optical clarity than isotactic polypropylene..$^{2-3}$ Poly(vinyl ether)s also showed a significant tacticitydependent properties, ${ }^{4,5}$ and the earlier reports on stereoselective cationic polymerization of vinyl ethers (VEs) can even date back to the late $1940 \mathrm{~s}^{6-8}$ However, in comparison to the coordination-insertion polymerizations that proceed at a non-planar chain-end with a relatively defined stereochemistry, the cationic polymerizations of vinyl ether monomers proceed with a planar $\mathrm{sp}^{2}$-hydridized carbocation (Figure 1, A) ${ }^{6,9-11}$ The planar configuration of this active carbocation with a large open space, together with the high polymerization rate, result in the difficulty in the development of a highly stereoselective cationic polymerization of vinyl ethers. Therefore, an additional stereochemical controls are normally required to set the stereochemistry at the planar, prechiral carbocationic center in the C-C bond formation step with the incoming vinyl ether monomer.

In the past seven decades, there are many attempts with a focus on the catalyst development, aiming to establish a stereoselective cationic polymerization of vinyl ethers to access (semi)crystalline poly(vinyl ether) products (Figure 1B, I). ${ }^{6,712-24}$ In 1999, Sawamoto and coworkers reported high levels of tacticity by using $\mathrm{TiCl}_{4} /$ phenoate complexes as the catalyst, ${ }^{15}$ and they later on found a combination of $\mathrm{SnCl}_{4}$ Lewis acid with bulky phosphoric acid ligand was also effective. ${ }^{17}$ Recently, Leibfarth et al. introduced chiral 1,1'-bi-2-naphthol (BINOL)-derived phosphoric acids into $\mathrm{TiCl}_{4}$-based Lewis acids and achieved a remarkable high content of meso diads (up to $94 \% \mathrm{~m}$ ). ${ }^{5,21}$
Very recently, Aoshima and co-workers disclosed a titanium complex bearing enantiopure $\alpha, \alpha, \alpha^{\prime}, \alpha^{\prime}$-tetraaryl-2,2-disubstituted 1,3-dioxolane4,5-dimethanol (TADDOL) ligands, which could provide poly(VE)s with isotacticity ranging from $83 \%$ to $94 \% \mathrm{~m}^{22}$ Whereas, the everincreasing demand for metal-free polymer materials in metal-sensitive fields such as microelectronic and biomedical applications, ${ }^{25,26}$ encouraged us to seek an organic catalyst to establish a metal-free stereoselective polymerization of vinyl ethers.

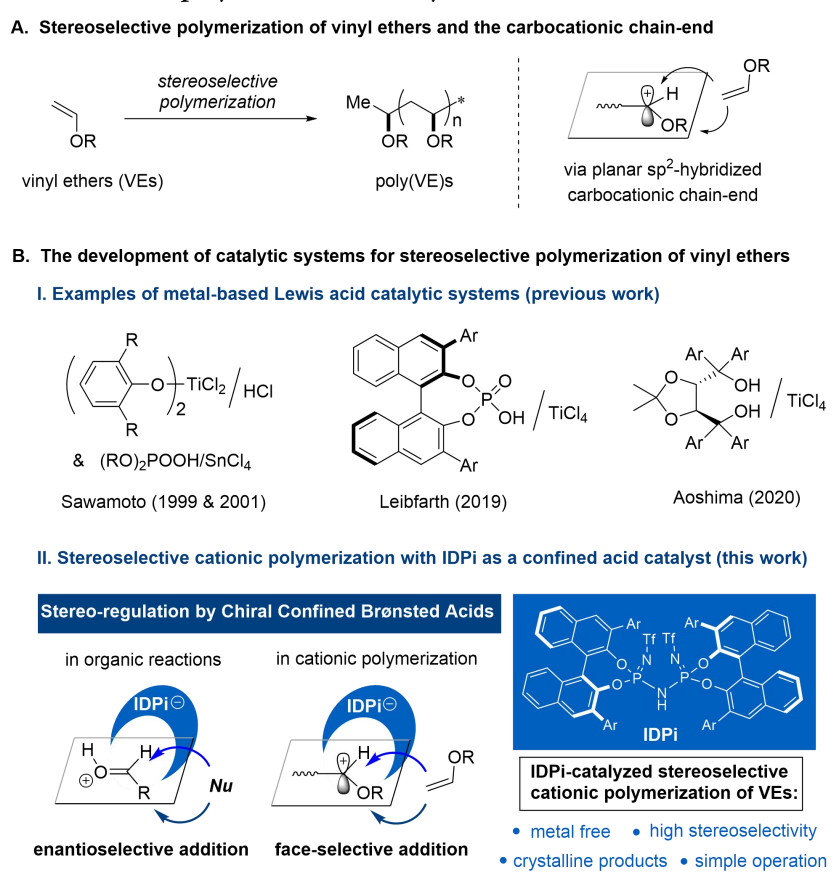

Figure 1. (A)Stereoselective polymerization of vinyl ethers. (B) The development of catalytic systems: metal-based Lewis catalysts (previous work) and metal-free confined acid catalysts (this work).

In fact, Brønsted acids (e.g. $\mathrm{HCl}, \mathrm{TfOH}, \mathrm{Tf}_{2} \mathrm{NH}$, etc.) are known capable to promote the cationic polymerization of vinyl ethers, but lack of effective stereochemical controls..$^{27-31}$ Our research experience ${ }^{32}$ on the asymmetric catalysis with chiral confined Brønsted acids, ${ }^{33-42}$ and particularly, the unprecedented high efficiency and stereoselectivity observed with the imidodiphosphorimidate (IDPi)-type confined acids in many transformation $\mathrm{s}^{33,35-42}$ encouraged us to explore the potential of these confined acids in polymer synthesis. ${ }^{43}$ Inspiringly, the acid activation of aldehydes by protonation of the carbonyl oxygen of the aldehydes, for example, in the asymmetric [4+2]-cycloaddition of 
dienes with aldehydes, ${ }^{37}$ generated an oxocarbenium ion ${ }^{36-38}$ that resembles the prechiral carbocationic chain-end of cationic polymerization of vinyl ethers (Figure 1B, II). We thus conceived, similar to the stereo-control in organic reactions, the chiral Brønsted acid anion ${ }^{44-50}$ around this propagating carbocationic chain-end could also provide a stereochemical micro-environment to govern the trajectory of the incoming vinyl ether monomer, thus establish a stereoselective cationic polymerization. Here, we report our efforts toward this goal, and the first establishment of a stereoselective cationic polymerization of vinyl ethers by employing a confined Brønsted acid, IDPi, as the catalyst, which features its metal free condition, high stereoselectivity, and operational simplicity. ${ }^{51}$

We commenced our investigation with the cationic polymerization of isobutyl vinyl ether (IBVE) in toluene $(0.4 \mathrm{M})$ at $-78^{\circ} \mathrm{C}$ with a series of imidodiphosphorimidates (IDPi 1a-1h) as the catalyst, which can be easily prepared from the corresponding 3,3'-substitued BINOLs ${ }^{33}$ (Table 1). For comparison with the confined Brønsted acids, a small acid catalyst $\left(\mathrm{Tf}_{2} \mathrm{NH}\right)$ was also examined under the same conditions (entry 1). As shown in Table $1, \mathrm{Tf}_{2} \mathrm{NH}$ delivered a rapidly polymerization, but the poly(isobutyl vinyl ether) $(M n=13000 \& \mathrm{D}=$ 1.62) was obtained as a fluid, which is consistent with its low isotacticity $(60 \% \mathrm{~m})$ determined by ${ }^{13} \mathrm{C}$ NMR analysis of the backbone methylene resonances ( $\delta 39$ to $42 \mathrm{ppm}$ ). To our delight, the confined acid IDPi 1a provided the poly(IBVE) with a remarkable high degree of isotacticity $(88 \% \mathrm{~m}$, entry

Table 1. Optimization of Confined Brønsted Acid for the Stereoselective Cationic Polymerization of IBVE. ${ }^{a}$

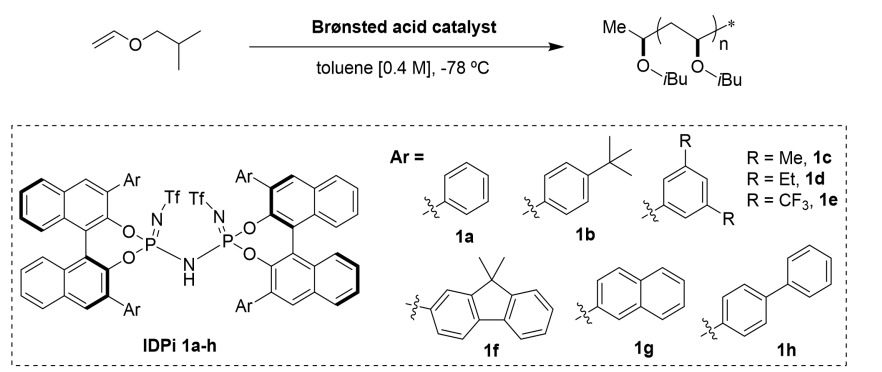

\begin{tabular}{ccccc}
\hline Entry & CAT & $M n(\mathrm{~kg} / \mathrm{mol})^{b}$ & $\bigoplus^{b}$ & $m^{c}$ \\
\hline 1 & Tf 2 NH & 13.0 & 1.62 & $60 \%$ \\
2 & IDPi 1a & 12.1 & 1.71 & $88 \%$ \\
3 & IDPi 1b & 9.7 & 1.40 & $79 \%$ \\
4 & IDPi 1c & 15.7 & 2.15 & $88 \%$ \\
5 & IDPi 1d & 24.9 & 2.09 & $87 \%$ \\
6 & IDPi 1e & 18.9 & 2.38 & $91 \%$ \\
7 & IDPi 1f & 14.0 & 2.58 & $80 \%$ \\
8 & IDPi 1g & 18.1 & 2.92 & $88 \%$ \\
9 & IDPi 1h & 12.8 & 2.34 & $81 \%$ \\
\hline
\end{tabular}

${ }^{a}$ Polymerization conditions: $[\mathrm{IBVE}]_{0} /[\text { Catalyst }]_{0}=200 / 1,[\mathrm{IBVE}]_{0}=$ $0.4 \mathrm{M}$ at $-78{ }^{\circ} \mathrm{C}$ for $30 \mathrm{~min} .{ }^{b}$ Determined by GPC using polystyrene standards. ${ }^{c}$ Determined by ${ }^{13} \mathrm{C}$ NMR analysis.
Table 2. Stereoselective Cationic Polymerization of Vinyl Ethers with IDPi 1e. ${ }^{a}$

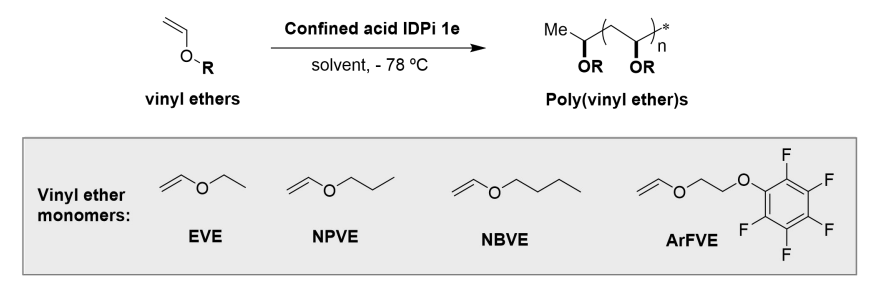

\begin{tabular}{|c|c|c|c|c|c|}
\hline Entry & VE & Solvent & $\begin{array}{l}M_{\mathrm{n}, \mathrm{GPC}}{ }^{b} \\
(\mathrm{~kg} / \mathrm{mol})\end{array}$ & $\bigoplus^{b}$ & $m^{c}$ \\
\hline 1 & IBVE & toluene & 18.9 & 2.38 & $91 \%$ \\
\hline 2 & IBVE & hex $/$ tol = 4:1 & 21.5 & 1.46 & $82 \%$ \\
\hline 3 & IBVE & hex $/$ tol = $1: 1$ & 20.8 & 1.65 & $85 \%$ \\
\hline 4 & IBVE & hex/tol = 1:4 & 28.1 & 2.33 & $87 \%$ \\
\hline $5^{d}$ & IBVE & toluene & 19.3 & 1.74 & $90 \%$ \\
\hline $6^{e}$ & IBVE & toluene & 16.9 & 1.62 & $90 \%$ \\
\hline $7^{f}$ & IBVE & toluene & 58.4 & 1.79 & $89 \%$ \\
\hline $8^{g}$ & IBVE & toluene & 101.0 & 1.68 & $86 \%$ \\
\hline 9 & EVE & toluene & 10.2 & 1.57 & $85 \%$ \\
\hline 10 & NPVE & toluene & 14.0 & 1.74 & $90 \%$ \\
\hline 11 & NBVE & toluene & 24.9 & 1.68 & $88 \%$ \\
\hline 12 & ArFVE & toluene & 34.8 & 1.79 & $89 \%$ \\
\hline
\end{tabular}

${ }^{a}$ Polymerization conditions: $[\mathrm{IBVE}]_{0} /[\text { IDPi 1e }]_{0}=200 / 1$ at $-78^{\circ} \mathrm{C}$ for $30 \mathrm{~min}$. hex = hexane; tol $=$ toluene. ${ }^{b}$ Determined by GPC using polystyrene standards. ${ }^{\circ}$ Determined by ${ }^{13} \mathrm{C}$ NMR analysis. ${ }^{d} 0.2 \mathrm{M}$ of IBVE was used. ${ }^{\mathrm{e}} 0.1 \mathrm{M}$ of IBVE was used. ${ }^{\mathrm{f}}$ Polymerization carried out at

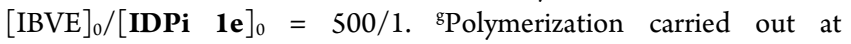
$[\text { IBVE }]_{0} /[\text { IDPi 1e }]_{0}=1200 / 1$.

2). This result demonstrated that the confined IDPi counterion could indeed control the stereoselectivity in the polymer chain growth. Inspired by this initial result, a series of IDPi acids were prepared and evaluated in the polymerization of IBVE. IDPi $\mathbf{1 b}$ with a tert-butyl substituent at the para positions of the phenyl groups was tested, but lower isotacticity $(79 \% \mathrm{~m})$ was observed (entry 3$)$. We thus decided to modify the 3,5-positions of the phenyl groups, which unveiled a high stereoselectivity with IDPi 1c (entry 4). Even though increasing the steric hindrance (IDPi 1d) led no further improvement in isotacticity (entry 5), the introduction of an electron-withdrawing trifluoromethyl group could enhance the isotacticity to a remarkable level of above $90 \%$ $\mathrm{m}$ (entry 6). Further variation on the aryl groups, including 9,9dimethylfluorene (IDPi 1f), naphthyl group (IDPi 1g), as well as an extended arm (IDPi 1h) afforded good stereoselectivities (80-88\% m, entries 7-9), but IDPi 1e remains the best, giving the highest isotacticity (91\% m, entry 6).

With IDPi le giving the highest isotacticity in the stereoselective cationic polymerization of IBVE, we further investigated its 
performance under other polymerization conditions (Table 2). The effect of adding non-polar solvent hexane was first examined by varying the hexane/toluene ratio. As shown in Table 2 (entries 1-4), the addition of hexane led to a lower isotacticity, while narrower dispersities were observed when compared with the polymerization conducted in toluene (entry 1). Decreasing the monomer concentration from $0.4 \mathrm{M}$ to $0.1 \mathrm{M}$ gradually narrowed down the molecular weight distributions of the obtained poly(IBVE)s, while maintaining the tacticity (entries 5-6). Further, poly(IBVE) with high molecule weights can be prepared with this method $\left(M_{\mathrm{n}}=58.4 \mathrm{~kg} / \mathrm{mol}\right.$, $101.0 \mathrm{~kg} / \mathrm{mol}$, entry 7 \& 8). This confined acid-catalyzed cationic polymerization method can also be applied to the polymerization of other vinyl ether monomers with high degrees of isotacticity (Table 2, entries 9-12). Under the optimized reaction conditions with IDPi 1e as the catalyst, the polymerization of small ethyl vinyl ether (EVE) could afford the corresponding poly(EVE) with good isotacticity $(85 \% \mathrm{~m}$, entry 9). The polymerization of other alkyl vinyl ethers, $n$-propyl vinyl ether (NPVE) and $n$-butyl vinyl ether (NBVE), gave poly(NPVE) and poly(NBVE) with $90 \% \mathrm{~m}$ and $88 \% \mathrm{~m}$, respectively (entry $10 \& 11$ ). To our delight, a fluorinated vinyl ether monomer, 1,2,3,4,5pentafluoro-6-(2-(vinyloxy)ethoxy)benzene (ArFVE) can also be polymerized with this confined acid-catalyzed polymerization method, to give the fluorinated poly(vinyl ether) product with high isotacticity ( $89 \% \mathrm{~m})$.

As shown in Figure 2, this chiral confined Brønsted acid-catalyzed stereoselective polymerization afforded the poly(IBVE) (Mn 99.3 $\mathrm{kg} / \mathrm{mol}, 90 \% \mathrm{~m})$ as semi-crystalline, white solids. In contrast, $\mathrm{Tf}_{2} \mathrm{NH}$ catalyzed polymerization gave a fluid with a glass transition temperature below $0{ }^{\circ} \mathrm{C}$. The poly(vinyl ether) products were further evaluated using differential scanning calorimetry (DSC). Poly(NPVE) ( $90 \% \mathrm{~m}$ ) displayed single melting transitions at $52{ }^{\circ} \mathrm{C}$, while poly(IBVE) $(90 \% \mathrm{~m})$ showed two melting transitions at 113 and 127 ${ }^{\circ} \mathrm{C}$.
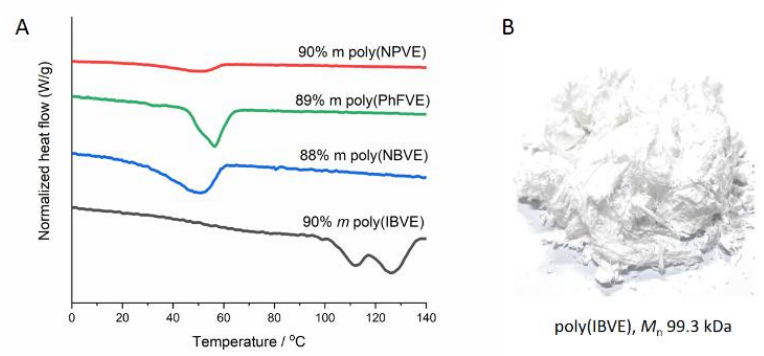

Figure 2. (A) DSC scan curves. (B) Photo of the poly(IBVE) product.

The IDPi-catalyzed stereoselective polymerization of vinyl ethers can also be employed in the one-pot synthesis the poly(vinyl ether)s with a chain-end functionalization by trapping the carbocationic chain-

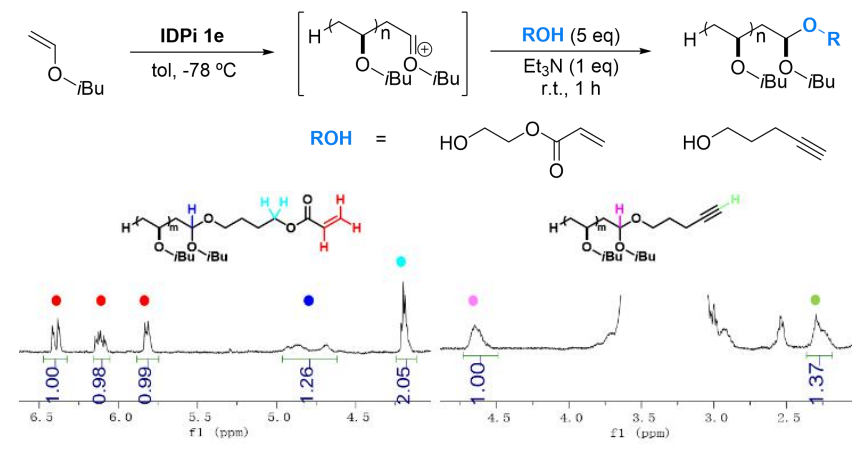

Figure 3. In situ chain-end functionalization and NMR characterization. ends in situ. As shown in Figure 3, upon full conversion of the IBVE monomers, functionalized alcohols and trimethylamine $\left(\mathrm{Et}_{3} \mathrm{~N}\right)$ were added under argon. After stirred for one hour at room temperature, the corresponding alcohol-trapped poly(vinyl ether)s can be obtained by precipitation in methanol. In this approach, poly(IBVE)s attached with an acrylate or alkyne functionality can be synthesized, which could allow further modifications at the chain ends.

In conclusion, a metal-free highly stereoselective cationic polymerization of vinyl ethers have been developed by employing IDPi-type chiral confined Brønsted acids as the catalyst. This organocatalytic approach could afforded poly(vinyl ether)s with high molecular weights and isotacticity, featuring its high efficiency, high stereoselectivity, single catalyst system, and operation simplicity. Moreover, a one-pot chain-end modification via in situ trapping of the oxocarbenium was also demonstrated. Further application of the confined Brønsted acids in other stereoselective cationic polymerizations can be expected.

\section{ASSOCIATED CONTENT}

\section{Supporting Information}

Synthesis of IDPi catalysts, experimental procedures, characterization data, copies of NMR spectra. The Supporting Information is available free of charge via the Internet at http://pubs.acs.org.

\section{AUTHOR INFORMATION}

\section{Corresponding Author}

E-mail:shliao@fzu.edu.cn

\section{Notes}

The authors declare no conflict of interests.

\section{ACKNOWLEDGMENT}

We gratefully acknowledge the Recruitment Program of Global Experts (1000plan), Beijing National Laboratory for Molecular Sciences (BNLMS201913), 100-Talent Project of Fujian, and Fuzhou University for the financial support.

\section{REFERENCES}

(1) Worch, J. C.; Prydderch, H.; Jimaja, S.; Bexis, P.; Becker, M. L.; Dove, A. P. Stereochemical Enhancement of Polymer Properties. Nat. Rev. Chem. 2019, 3 , 514-535.

(2) Busico, V. Giulio Natta and the Development of Stereoselective Propene Polymerization. Adv. Polym. Sci. 2013, 257, 37- 58.

(3) De Rosa, C.; Auriemma F. Structure and physical properties of syndiotactic polypropylene: A highly crystalline thermoplastic elastomer. Prog. Polym. Sci. 2006, 31, 145-237.

(4) Fishbein, L.; Crowe, B. F. The Relation of Structure to Some Physical and Mechanical Properties of Poly(Vinyl Alkyl Ethers). Makromol. Chem. 1961, 48, 221-228,

(5) Teator, A. J.; Leibfarth, F. A. Catalyst-Controlled Stereoselective Cationic Polymerization of Vinyl Ethers. Science 2019, 363, 1439-1443.

(6) Teator, A. J.; Varner, T. P.; Knutson, P. C.; Sorensen, C. C.; Leibfarth, F. A. 100th Anniversary of Macromolecular Science Viewpoint: The Past, Present, and Future of Stereocontrolled Vinyl Polymerization. ACS Macro Lett. 2020, 9, $1638-1654$.

(7) Aoshima, S.; Kanaoka, S. A Renaissance in Living Cationic Polymerization. Chem. Rev. 2009, 109, 5245-5287.

(8) Sawamoto, M. Modern Cationic Vinyl Polymerization. Prog. Polym. Sci. 1991, 16, 111-172. 
(9) Coates, G. W. Precise Control of Polyolefin Stereochemistry Using Single-Site Metal Catalysts. Chem. Rev. 2000, 100, 1223-1252.

(10) Chen, E. Y. X. Coordination Polymerization of Polar Vinyl Monomers by Single-Site Metal Catalysts. Chem. Rev. 2009, 109, 5157-5214.

(11) Kamigaito, M.; Satoh, K. Stereospecific Living Radical Polymerization: Dual Control of Chain Length and Tacticity for Precision Polymer Synthesis. Chem. Rev. 2009, 109, 5120-5156.

(12) Aoshima, S.; Ito, Y.; Kobayashi, E. Stereoregularity of Poly(Vinyl Ether)s with a Narrow Molecular Weight Distribution Obtained by the Living Cationic Polymerization. Polym. J. 1993, 25, 1161-1168.

(13) Kamigaito, M.; Maeda, Y.; Sawamoto, M.; Higashimura, T. Living Cationic Polymerization of Isobutyl Vinyl Ether by Hydrogen Chloride/Lewis Acid Initiating Systems in the Presence of Salts: In-Situ Direct NMR Analysis of the Growing Species1. Macromolecules 1993, 26, 1643-1649.

(14) Aoshima, S.; Ito, Y.; Kobayashi, E. Stereoregularity of Poly(Vinyl Ether)s with a Narrow Molecular Weight Distribution Obtained by the Living Cationic Polymerization. Polym. J. 1993, 25, 1161-11681.

(15) Ouchi, M.; Kamigaito, M.; Sawamoto, M. Stereoregulation in Cationic Polymerization by Designed Lewis Acids. 1. Highly Isotactic Poly(Isobutyl Vinyl Ether) with Titanium-Based Lewis Acids. Macromolecules 1999, 32, 6407-6411.

(16) Ouchi, M.; Kamigaito, M.; Sawamoto, M. Stereoregulation in Cationic Polymerization by Designed Lewis Acids. II. Effects of Alkyl Vinyl Ether Structure. J. Polym. Sci., Part A: Polym. Chem. 2001, 39, 1060-1066.

(17) Ouchi, M.; Sueoka, M.; Kamigaito, M.; Sawamoto, M. Stereoregulation in Cationic Polymerization. III. High Isospecificity with the Bulky Phosphoric Acid $\left[(\mathrm{RO})_{2} \mathrm{PO}_{2} \mathrm{H}\right] / \mathrm{SnCl}_{4}$ Initiating Systems: Design of Counteranions via Initiators. J. Polym. Sci., Part A: Polym. Chem. 2001, 39, 1067-1074.

(18) Kawaguchi, T.; Sanda, F.; Masuda, T. Polymerization of Vinyl Ethers with Transition-Metal Catalysts: An Examination of the Stereoregularity of the Formed Polymers. J. Polym. Sci., Part A: Polym. Chem. 2002, 40, 3938-3943.

(19) Sudhakar, P.; Vijayakrishna, K. Highly Stereoselective Living Polymerization of Vinyl Ethers at Ambient Temperature Mediated by Chiral Titanium Complexes. Chem CatChem 2010, 2, 649- 652.

(20) Kanazawa, A.; Kanaoka, S.; Aoshima, S. A Stepping Stone to Stereospecific Living Cationic Polymerization: Cationic Polymerization of Vinyl Ethers Using Iron(II) Sulfate. J. Polym. Sci., Part A: Polym. Chem. 2010, 48, 3702-3708.

(21) Teator, A. J.; Varner, T. P.; Jacky, P. E.; Sheyko, K. A.; Leibfarth, F. A. Polar Thermoplastics with Tunable Physical Properties Enabled by the Stereoselective Copolymerization of Vinyl Ethers. ACS Macro Lett. 2019, 8, 1559-1563.

(22) Watanabe, H.; Yamamoto, T.; Kanazawa, A.; Aoshima, S. Stereoselective Cationic Polymerization of Vinyl Ethers by Easily and Finely Tunable Titanium Complexes Prepared from Tartrate-Derived Diols: Isospecific Polymerization and Recognition of Chiral Side Chains. Polym. Chem. 2020, 11, 3398-3403.

(23) Varner, T. P.; Teator, A. J.; Reddi, Y.; Jacky, P. E.; Cramer, C. J.; Leibfarth, F. A. Mechanistic Insight into the Stereoselective Cationic Polymerization of Vinyl Ethers. J. Am. Chem. Soc. 2020, 142, 17175-17186.

(24) Uchiyama, M.; Satoh, K.; Kamigaito, M. Stereospecific Cationic RAFT Polymerization of Bulky Vinyl Ethers and Stereoblock Poly(Vinyl Alcohol) via Mechanistic Transformation to Radical RAFT Polymerization of Vinyl Acetate. Giant 2021, 5, 100047.

(25) Shanmugam, S.; Boyer, C. Organic photocatalysts for cleaner polymer synthesis. Science 2016, 352, 1053-1054.

(26) Albertsson, A. C.; Varma, I. K. Recent Developments in Ring Opening Polymerization of Lactones for Biomedical Applications. Biomacromolecules 2003, 4, 1466-1486.

(27) Sugihara, S.; Tanabe, Y.; Kitagawa, M.; Ikeda I. Facile metal-free living cationic polymerization of various vinyl ethers by hydrogen chloride with ether. J. Polym. Sci., Part A: Polym. Chem. 2008, 46, 1913-1918.

(28) Uchiyama, M.; Satoh, K.; Kamigaito, M. Cationic RAFT Polymerization Using ppm Concentrations of Organic Acid. Angew. Chem., Int. Ed. 2015, 54, 1924-1928.

(29) Sugihara, S.; Konegawa, N.; Maeda, Y. HCl-Et ${ }_{2} \mathrm{O}-$ Catalyzed Metal-Free RAFT Cationic Polymerization: One-Pot Transformation from Metal-Free
Living Cationic Polymerization to RAFT Radical Polymerization. Macromolecules 2015, 48, 5120-51316.

(30) Song, J.; Xu, J.; Tang, D. Rapid Living Cationic Polymerization of Vinyl Ethers by a Single-Molecular Initiating System. J. Polym. Sci., Part A: Polym. Chem. 2016, 54, 1373-1377.

(31) Kottisch, V.; Jermaks, J.; Mak, J.-Y.; Woltornist, R. A.; Lambert, T. H.; Fors, B. P. Hydrogen Bond Donor Catalyzed Cationic Polymerization of Vinyl Ethers. Angew. Chem. Int. Ed. 2021, 60, 4535-4539.

(32) Liao, S.; Čorić, I.; Wang, Q.; List, B. Activation of $\mathrm{H}_{2} \mathrm{O}_{2}$ by Chiral Confined Brønsted Acids: A Highly Enantioselective Catalytic Sulfoxidation. J. Am. Chem. Soc. 2012, 134, 10765-10768.

(33) Schreyer, L.; Properzi, R.; List, B. IDPi Catalysis. Angew. Chem., Int. Ed. 2019, 58, 12761-12777.

(34) Corić, I.; List, B. Asymmetric Spiroacetalization Catalysed by Confined Brønsted Acids. Nature 2012, 483, 315-3196.

(35) Kaib, P. S. J.; Schreyer, L.; Lee, S.; Properzi, R.; List, B. Extremely Active Organocatalysts Enable a Highly Enantioselective Addition of Allyltrimethylsilane to Aldehydes. Angew. Chem. Int. Ed. 2016, 55, 1320013203.

(36) Xie, Y.; Cheng, G. J.; Lee, S.; Kaib, P. S. J.; Thiel, W.; List, B. Catalytic Asymmetric Vinylogous Prins Cyclization: A Highly Diastereo- and Enantioselective Entry to Tetrahydrofurans. J. Am. Chem. Soc. 2016, 138, 14538-14541.

(37) Liu, L.; Kim, H.; Xie, Y.; Farès, C.; Kaib, P. S. J.; Goddard, R.; List B. Catalytic Asymmetric [4+2]-Cycloaddition of Dienes with Aldehydes. J. Am. Chem. Soc. 2017, 139, 13656-13659.

(38) Lee, S.; Kaib, P. S. J.; List, B. Asymmetric Catalysis via Cyclic, Aliphatic Oxocarbenium Ions. J. Am. Chem. Soc. 2017, 139, 2156-2159.

(39) Schreyer, L.; Kaib, P. S. J.; Wakchaure, V. N.; Obradors, C.; Properzi, R.; Lee, S.; List, B. Confined Acids Catalyze Asymmetric Single Aldolizations of Acetaldehyde Enolates. Science 2018, 362, 216- 219.

(40) Tsuji, N.; Kennemur, J. L.; Buyck, T.; Lee, S.; Prévost, S.; Kaib, P. S. J.; Bykov, D.; Farès, C.; List, B. Activation of Olefins via Asymmetric Brønsted Acid Catalysis. Science 2018, 359, 1501-1505.

(41) Ouyang, J.; Kennemur, J. L.; De, C. K.; Farès, C.; List, B. Strong and Confined Acids Enable a Catalytic Asymmetric Nazarov Cyclization of Simple Divinyl Ketones. J. Am. Chem. Soc. 2019, 141, 3414-3418.

(42) Ghosh, S.; Das, S.; De, C. K.; Yepes, D.; Neese, F.; Bistoni, G.; Leutzsch, M.; List, B. Strong and Confined Acids Control Five Stereogenic Centers in Catalytic Asymmetric Diels-Alder Reactions of Cyclohexadienones with Cyclopentadiene. Angew. Chem. Int.Ed. 2020, 59, 12347-12351.

(43) Zhang, X.; Jiang, Y.; Ma, Q.; Hu, S.; Wang, Q.; Liao, S.

Imidodiphosphorimidate (IDPi) as an Efficient Organocatalyst for Controlled/Living Ring-Opening Polymerization of Lactones. Eur. Polym. J. 2020, 123: 109449.

(44) Mitschke, B.; Turberg, M.; List, B. Confinement as a Unifying Element in Selective Catalysis. Chem 2020, 6, 2515-2532.

(45) Schwengers, S. A.; De, C. K.; Grossmann, O.; Grimm, J. A. A.; Sadlowski, N. R.; Gerosa, G. G.; List, B. Unified Approach to Imidodiphosphate-Type Brønsted Acids with Tunable Confinement and Acidity. J. Am. Chem. Soc. 2021, 143, 14835-14844.

(46) Mahlau, M.; List, B. Asymmetric Counteranion-Directed Catalysis: Concept, Definition, and Applications. Angew. Chem., Int. Ed. 2013, 52, 518533.

(47) Brak, K.; Jacobsen, E. N. Asymmetric Ion-Pairing Catalysis. Angew. Chem., Int. Ed. 2013, 52, 534-561.

(48) Phipps, R. J.; Hamilton, G. L.; Toste, F. D. The Progression of Chiral Anions from Concepts to Applications in Asymmetric Catalysis. Nat. Chem. 2012, 4, 603-614.

(49) Liao, S.; List, B. Asymmetric Counteranion-Directed Transition-Metal Catalysis: Enantioselective Epoxidationof Alkenes with Manganese(III)-Salen Phosphate Complexes, Angew. Chem. Int. Ed., 2010, 49, 628-631.

(50) Merten, C.; Pollok, C. H.; Liao, S.; List, B. Stereochemical Communication within a Chiral Ion Pair Catalyst. Angew. Chem. Int. Ed. 2015, $54,8841-8845$.

(51) A patent has been filed on this stereoselective polymerization method employing chiral confined Brønsted acids as the catalyst. 


\section{Table of Content}

Confined Acid-Catalyzed Stereoselective Cationic Polymerization of Vinyl Ethers:

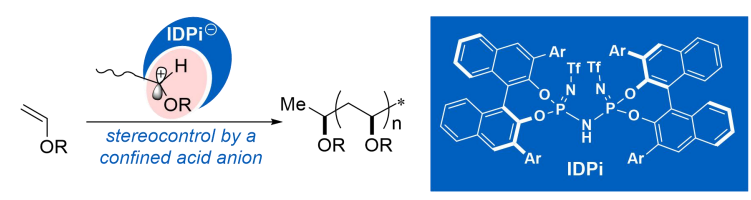

vinyl ethers (VEs) isotactic PVEs IDPi-Confined Brønsted Acids 